\title{
ANÁLISE ESTRUTURAL RÚPTIL NA ZONA DE INFLUÊNCIA DO ARCO DE PONTA GROSSA: ESTUDO DE CASO NA ÁREA DA UHE-MAUÁ-PR
}

\author{
BRITTLE STRUCTURAL ANALYSIS IN THE INFLUENCE ZONE OF THE PONTA GROSSA \\ ARCH: CASE STUDY IN THE AREA OF THE HPP-MAUÁ-PR
}

\section{Ramon Sade Zapata RIVAS, Eduardo SALAMUNI, Isabella Françoso Rebutini FIGUEIRA}

Universidade Federal do Paraná, Setor de Ciências da Terra - Programa de Pós-Graduação em Geologia. Rua XV de Novembro, 1.299, Centro. Curitiba - PR. E-mails: ramonzapata.geo@gmail.com; salamuni@ufpr.br; isabella.figueira@lactec.org.br

\author{
Introdução \\ Localização \\ Arcabouço geológico e tectônico \\ Materiais e métodos \\ Resultados \\ Análises geométrica e cinemática \\ Análise de dados de campo \\ Análise cinemática e dinâmica \\ Discussão \\ Conclusões \\ Agradecimentos \\ Referências bibliográficas
}

\begin{abstract}
RESUMO - A pesquisa foi realizada no entorno da Usina Hidrelétrica de Mauá (UHE-Mauá), localizada no rio Tibagi, a noroeste do município de Telêmaco Borba divisa com Ortigueira, região central do Estado do Paraná. O local em que a usina está implantada é formado por soleira de diabásio aflorante, pertencente à Formação Serra Geral, intrudida em rochas sedimentares paleozoicas da Bacia do Paraná. No local o controle estrutural se dá em função da intersecção de estruturas regionais como o Arco de Ponta Grossa, localizado entre as Zonas de Falha São Jerônimo-Curiúva e a Zona de Falha Jacutinga. A análise estrutural possibilitou o reconhecimento de falhas, com predomínio de azimute N50-60E em mesoescala. Em fotointerpretação, no entanto, os lineamentos mais marcantes possuem azimute N40-50W. As descontinuidades mapeadas são caracterizadas, principalmente por juntas, falhas e zonas de falhas cataclásticas associadas a regime tectônico transcorrente, por vezes transtensivo com formação de estrutura em flor negativa e falhas oblíquas, identificadas nos sedimentos paleozoicos e nas rochas básicas. Este trabalho aponta a existência de pelo menos dois pulsos de deformação pós-cretácicos, que deformaram a soleira de diabásio e o conjunto de rochas sedimentares encaixantes, alterando o comportamento reológico da rocha e a disposição geométrica final dos grandes planos de fraquezas. O primeiro está ligado a um campo de paleotensão variável entre NNE-SSW e NNW-SSE e o segundo a um campo de paleotensão variável entre WNW-ESSE e ENE-WSW.
\end{abstract}

Palavras-chave: Análise estrutural; Tectônica rúptil; Falhas transcorrentes; Paleotensão.

\begin{abstract}
The research was carried out in the surroundings the Mauá Hydroelectric Power Plant (UHE-Mauá), located on the Tibagi River, northwest of the Telêmaco Borba municipality, central region of the Paraná State. The power plant's site is underlain by a diabase sill of the Serra Geral Formation, intruded on Paleozoic sedimentary rocks of the Paraná Basin. At the site, structural control occurs due to the intersection of regional structures, such as the Ponta Grossa Arc, located between the São Jerônimo-Curiúva Fault Zones and the Jacutinga Fault Zone. Results from the mesoscale structural analysis allowed the recognition of faults having a dominant N50-60E orientation. In photo interpretation, however, the most striking lineaments have N40-50W azimuth direction.The mapped discontinuities are characterized, mainly by joints, faults and cataclastic fault zones associated with a strike-slip tectonic regime, sometimes transtensive causing negative flower structures and oblique faults, identified in Paleozoic sediments and basic rocks. This work points to the existence of at least two post-Cretaceous deformation pulses, which deformed the diabase sill and the set of sedimentary rocks, altering the rheological behavior of the rock and the final geometric arrangement of the large weakness planes. The first deformation pulse is related to paleostress field ranging between NNE-SSW and NNW-SSE, whilst the second deformation pulse is coherent to a paleostress field varying between WNW-ESSE and ENE-WSW.
\end{abstract}

Keywords: Structural analysis; Brittle tectonics; Strike-slip faults; Paleostress.

\section{INTRODUÇÃO}

O Arco de Ponta Grossa é uma feição tectônica de grande expressão regional com geometria alongada e eixo de direção NW-SE, responsável pelo arqueamento da porção central das unidades da Bacia do Paraná. No arco há lineamentos magnéticos de expressão regional (Ferreira, 1982) que correspondem a falhas e feixes de fraturas preenchidas por um largo enxame de diques de diabásio. Neste cenário também ocorrem zonas de fraqueza de direção NE-SW, produzidas pela reativação de falhas brasilianas que seccionaram o embasamento local. A Zona de Falha (ZF) Jacutinga (Rostirolla et al., 2000) é uma dessas estruturas que afetam 
unidades paleozoicas e mesozoicas e está na zona de influência da área estudada.

O local da pesquisa está inserido no contexto geológico da Bacia Sedimentar do Paraná, tendo sido favorecido pelo acesso a novos afloramentos expostos no canteiro de obras da Usina Hidrelétrica (UHE) de Mauá. A região está sob influência litoestrutural da intersecção de lineamentos morfoestruturais e falhas existentes no flanco nordeste do Arco de Ponta Grossa. Cabe destacar que, anteriormente à implantação da usina e seu respectivo reservatório, houve registros de sismos, de baixa magnitude (menores que 4,0 Mb) em sua área de influência, como os registros de episódios de 2006, com epicentro nas cidades de Telêmaco Borba e Ortigueira.

Mais recentemente foram registrados tremores de magnitudes inferiores a $1,9 \mathrm{Mb}$, com epicentro em cidade de Londrina, a cerca de $150 \mathrm{~km}$ de distância.
A investigação geológico-estrutural na região buscou levantar dados e analisar as estruturas geradas pela deformação de soleira de diabásio que serve, em parte, de substrato do eixo da barragem. O objetivo principal da pesquisa é o de contribuir com novos dados e informações, preenchendo lacunas de conhecimento do contexto tectônico regional do Arco de Ponta Grossa, setor centro-nordeste, correlacionando os dados obtidos e sua interpretação com o que já foi apresentado em trabalhos anteriores (Figueira 2004; Strugale et al. 2003; 2007).

Os resultados foram obtidos a partir da interpretação de lineamentos em imagens de satélite e fotografias aéreas em escala regional, integração de dados estruturais de campo e análise estrutural destas estruturas para a determinação da geometria, dos mecanismos de deformação rúptil e paleotensão, bem como a correlação cronológica relativa dos pulsos tectônicos deduzidos.

\section{LOCALIZAÇÃO}

A área de estudo está situada no domínio da Usina Hidrelétrica de Mauá (UHE-Mauá), centronorte do estado do Paraná, trecho médio do rio Tibagi, entre os municípios de Telêmaco Borba e
Ortigueira (Figura 1). O acesso ao local se faz a partir da sede municipal de Telêmaco Borba, por meio de vias municipais e estradas vicinais não pavimentadas.
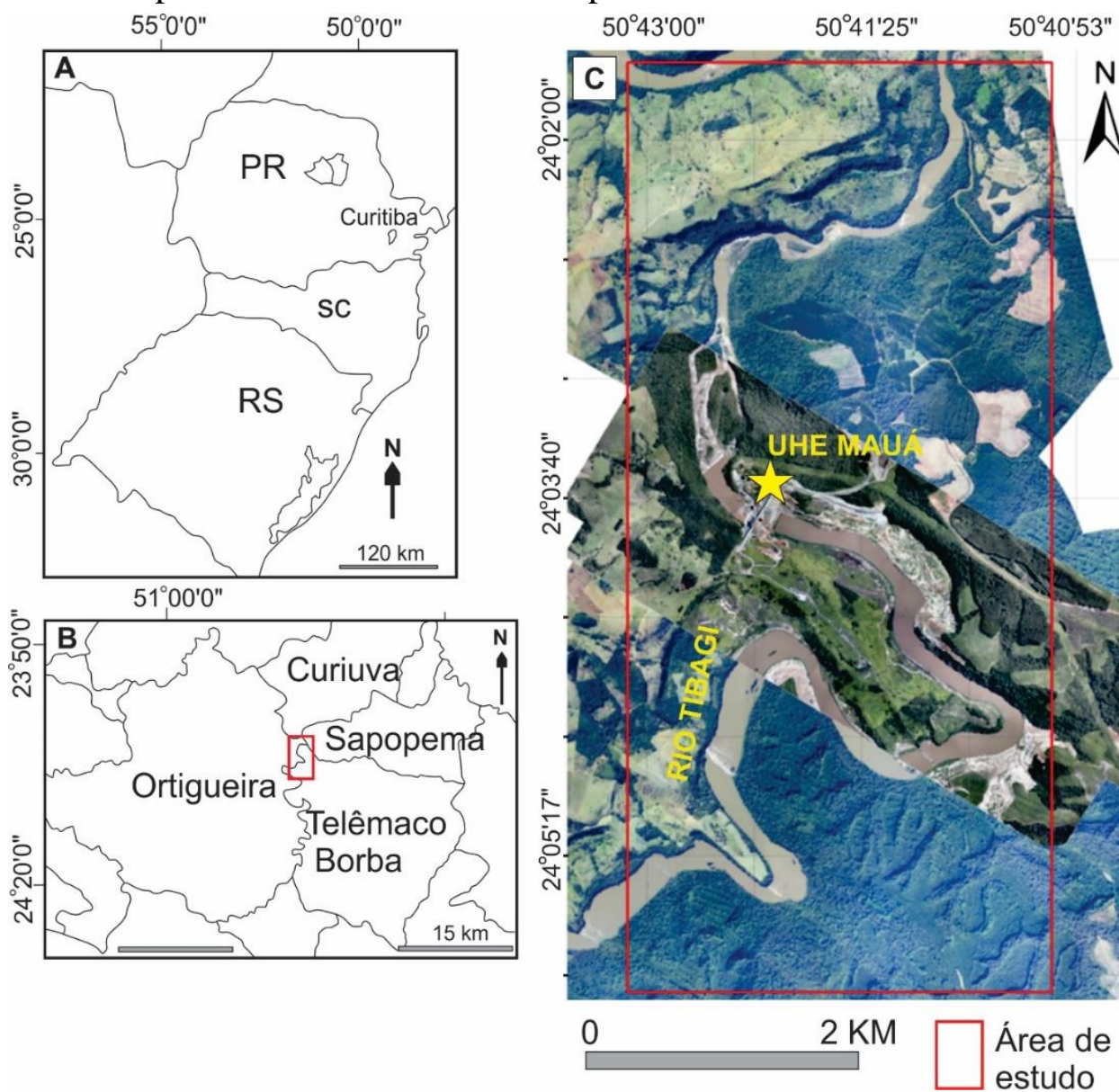

Figura 1 - Localização da área de estudo: (A) e (B) localização regional e municipal e (C) conjunto de ortofotos sobrepostas, como o polígono da área em vermelho. 


\section{ARCABOUÇO GEOLÓGICO E TECTÔNICO}

A Bacia do Paraná é uma ampla bacia intracratônica com registro estratigráfico que consiste, basicamente, em cinco sequências deposicionais, com aporte de sedimentos que se iniciam no Ordoviciano Superior e culminam no Cretáceo Superior. Trata-se de uma sinéclise localizada na porção meridional do território brasileiro, estendendo-se ao nordeste da Argentina, oriente do Paraguai e norte do Uruguai (Milani et al. 2007).

$\mathrm{O}$ arcabouço estratigráfico da área (Figura 2A) é composto por unidades rochosas de diferentes períodos geológicos, como a Supersequência Gondwana I (CarboníferoEotriássico) e a Gondwana II (Meso a Neotriássico) (Milani et al. 2007). As unidades sedimentares paleozoicas aflorantes representam o máximo afogamento da bacia, já as unidades magmáticas presentes são reflexos da fragmentação do Gondwana, que ocasionou o soerguimento da bacia no período mesozoico e em profundos fraturamentos da crosta que serviram como condutos de fluxo do magma basáltico. As associações sedimentares no local de estudo são compostas por rochas siliciclásticas da Formação Palermo, Irati e Serra Alta, de idade Eopermiana, intrudidas por soleiras e diques de diabásio pertencentes à Formação Serra Geral de idade Barremiana (Milani et al. 2007). A soleira possui forma irregular na superfície apresentando-se mais larga a noroeste e estreita na região no sítio do eixo de barramento da usina.

Dados aeromagnetométricos desenham importantes lineamentos de caráter regional paralelos à feição do Arco de Ponta Grossa, denominados de São Jerônimo-Curiúva, Rio Alonzo, Rio Piquiri e Guapiara (Ferreira, 1982; Zalán et al. 1990).

Esses lineamentos demarcam grandes traços do arcabouço estrutural do embasamento que se propagam nos sedimentos da Bacia do Paraná (Figura 2B). Os lineamentos São JerônimoCuriúva e Rio Alonzo delimitam a charneira do arco a nordeste e a sudoeste, respectivamente (Figura 2B), e limitam o enxame de diques de diabásio toleítico de direção NW-SE. O Arco de Ponta Grossa é responsável pela flexura antiformal de sedimentos e zonas de falhas. Em sua charneira há a Zona de Falha MaringáCuritiba, provável reativação de estrutura do embasamento proterozoico.

O principal lineamento magnético destacado na região de interesse, Lineamento São Jerônimo-Curiúva, apresenta indícios de atividade tectônica pós-cretácica. A tectônica que nucleou esse alinhamento foi responsável pela formação de falhas transtensionais, posteriormente reativadas como normais permitindo o preenchimento pelos diques até o final do Aptiano, bem demarcados nas unidades sedimentares da Bacia do Paraná e quase todos circunscritos às zonas de falha São JerônimoCuriúva e Rio Alonzo. Em toda a porção oeste do local estudado há feixes de lineamentos de menor expressão regional, tais como as Zonas de Falhas (ZF) Tamarana, Incrão e Mauá da Serra. Apresentam-se retilíneas a anastomosadas e podem estar intrudidos por diques de diabásio.

O principal lineamento magnético destacado na região de interesse, Lineamento São Jerônimo-Curiúva, apresenta indícios de atividade tectônica pós-cretácica. A tectônica que nucleou esse alinhamento foi responsável pela formação de falhas transtensionais, posteriormente reativadas como normais permitindo o preenchimento pelos diques até o final do Aptiano, bem demarcados nas unidades sedimentares da Bacia do Paraná e quase todos circunscritos às zonas de falha São JerônimoCuriúva e Rio Alonzo. Em toda a porção oeste do local estudado há feixes de lineamentos de menor expressão regional, tais como as Zonas de Falhas (ZF) Tamarana, Incrão e Mauá da Serra. Apresentam-se retilíneas a anastomosadas e podem estar intrudidos por diques de diabásio.

Outra feição importante que influencia a estruturação interna das rochas aflorantes no local de estudo é a ZF Jacutinga, correspondente a uma falha neoproterozoica com direção NESW, presente no embasamento da Bacia do Paraná (Soares 1991). É uma das mais importantes estruturas que seccionam a bacia, estendendo-se desde a região de Misiones, na Argentina, até o sul de Minas Gerais, passando pelo município de Anhembi (SP) (Soares et al., 1996). Tal estrutura separa terrenos do Maciço de Guaxupé e da Faixa Brasília, a norte, das rochas proterozoicas das faixas Ribeira (Apiaí/São Roque) e Dom Feliciano, a sul (Cordani et al., 1984; Campanha \& Sadowski, 1999). Dois eventos deformacionais demarcam reativações 
da $\mathrm{ZF}$ Jacutinga. $\mathrm{O}$ primeiro teve caráter transpressivo com cinemática NE-SW sinistral, interpretado como resultado da orogenia $\mathrm{La}$ Ventana, na passagem Permiano-Triássico e o segundo transcorrente, extensional dextral ao longo das falhas NE-SW, durante e/ou após o magmatismo Serra Geral no Mesozoico Rostirolla et al. (2000).

\section{$50^{\circ} 45^{\prime} 15^{\prime \prime}$}

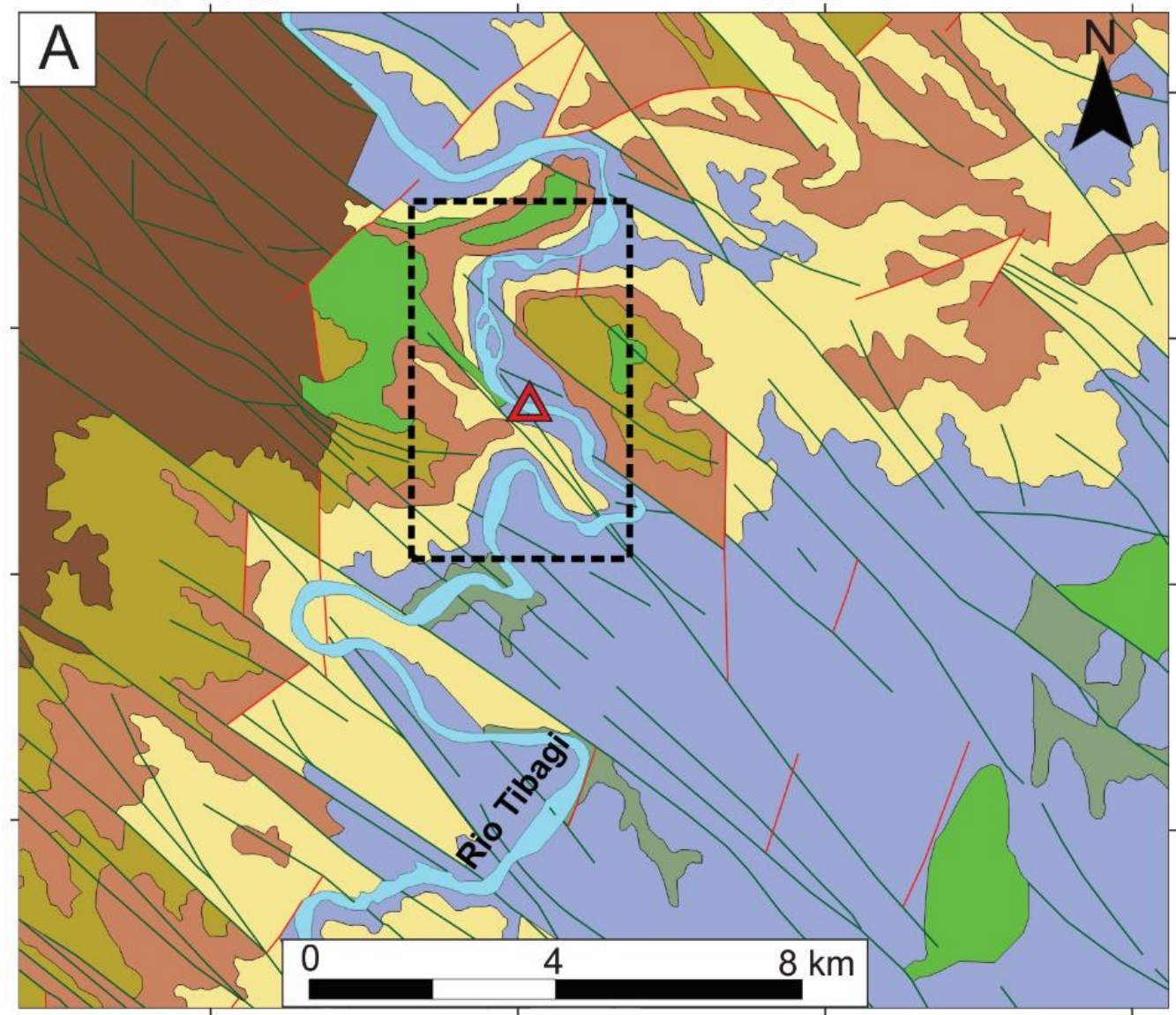

\section{Legenda}

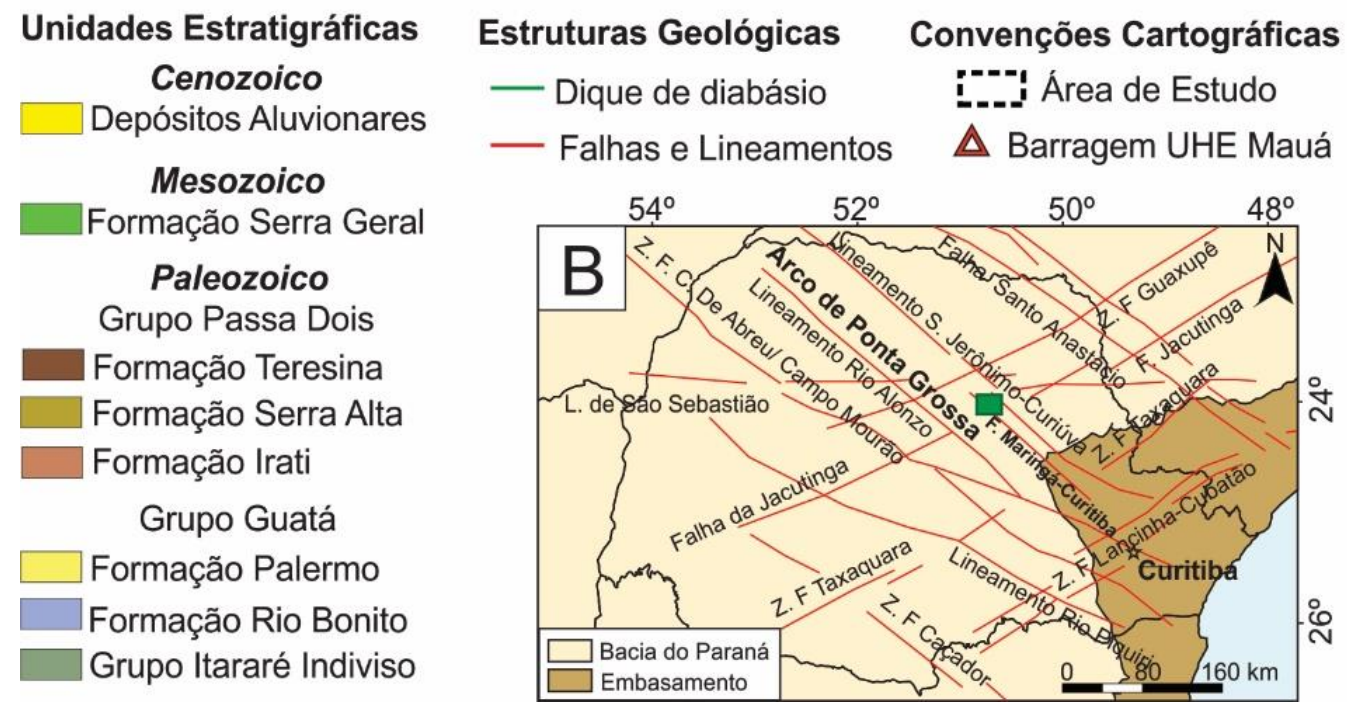

Figura 2 - (A) Mapa geológico local do entorno da UHE Mauá; (B) arcabouço geológico-estrutural do Paraná com os seus principais lineamentos. Fontes: Mineropar (2006), Zalán et al. (1990) e VLB ENGENHARIA (2007).

\section{MATERIAIS E MÉTODOS}

A pesquisa foi inicialmente embasada em informações preliminares levantadas a respeito da tectônica mezo-cenozoica na região Sul e Sudeste do Brasil, com o intuito de comparar os resultados do presente estudo com propostas temáticas semelhantes em trabalhos anteriores.

Os lineamentos de relevo foram traçados em imagens Landsat e em fotografias aéreas, 
respectivamente. Por meio de fotointerpretação foi possível a identificação de estruturas regionais de $1^{\mathrm{a}}$ ordem (na escala 1:100.000) com propriedades de maior comprimento $\mathrm{e}$ continuidade lateral do traçado de estruturas de $2^{\mathrm{a}}$ ordem, denominadas de "locais" (na escala 1:25.000), com aspecto determinado tanto por menor comprimento quanto por menor continuidade, porém de caráter mais pervasivo. A análise em diferentes escalas permitiu o entendimento do arcabouço estrutural pretérito do substrato, representado por morfoestruturas na superfície.

A partir da correlação dos vários mapas de lineamentos, utilizando-se do ArcGis 10.1® e sua ferramenta de expressões de cálculo do ArcMap, foram gerados diagramas de rosetas.

Foram analisadas 21 estações de campo (afloramentos de escalas diversas), distribuídas no perímetro da Usina Hidrelétrica de Mauá, desde a região à montante do eixo de barramento até o entorno da câmara de carga e casa de força. As melhores exposições de evidências tectônicas ocorrem na soleira de diabásio da Formação Serra Geral, de tal forma que os planos de falhas bem preservados e com boa continuidade lateral, o que facilitou a coleta de dados estruturais.

O levantamento geológico-estrutural permitiu a obtenção e análise de 512 atitudes de fraturas (falhas e juntas), descritas com base na geometria, orientação, espaçamento, abertura, rugosidade e indicadores cinemáticos. Os indicadores foram caracterizados por planos de falhas, juntas de cisalhamento, estrias (slickensides e slickenlines), degraus (steps), crescimento de minerais, estruturas em crescente, de arrasto ou escalonadas.

As fraturas descritas com detalhes permitiram determinar as relações de corte entre diferentes famílias, inclusive em função da sobreposição de estrias. Assim, foi possível estabelecer uma ordem cronológica relativa entre os pulsos de deformação estimados para a área. A análise estrutural cinemática com os dados de estruturas rúpteis (falhas e juntas) tiveram por base os trabalhos de Petit (1987), Angelier (1994) e Doblas (1998), que abordam o uso dos indicadores cinemáticos em falhas.

As informações estruturais foram separadas num banco de dados por sistemas de fraturas mais pervasivas, conforme os seguintes sistemas encontrados na área: (a) Sistema NE-SW, falhas entre N40-50E e N60-70E; (b) Sistema N-S, falhas entre N10-20E e N10-20W; (c) Sistema NW-SE, falhas entre N30-50W e (d) Sistema E$\mathrm{W}$, falhas entre N70-90E e N80-90W.

Os estereogramas de densidade foram gerados nos softwares Stereo32 e GeotecStereo para a determinação dos campos de paleotensão responsáveis pela formação de juntas e falhas presentes no local de estudo. Para esse objetivo foi utilizado o software Sigma (Freitas, 2005).

\section{RESULTADOS}

\section{Análises Geométrica e Cinemática}

$\mathrm{O}$ traçado de lineamentos regionais e locais são sintetizados na figura 3 , com destaque para os lineamentos positivos (em verde) que, por vezes, exibem prolongamentos superiores a 15 $\mathrm{km}$ e extensão além da área de estudo. Os lineamentos negativos ocorrem paralelamente às grandes feições positivas e frequentemente seccionam ou compartimentam essas morfoestruturas.

As estruturas com direção preferencial para NW-SE são recorrentes em praticamente toda extensão da área e exibem traçado contínuo de alta persistência, bem espaçadas e correspondem, em sua maioria, a falhas abertas, preenchidas por diabásio. Já os lineamentos de direção NE-SW consistem em traços de baixa persistência e maior segmentação em escala regional e afetam tanto os sedimentos quanto as soleiras de diabásio. De modo geral apresentam-se retilíneas e regionalmente controladas pela ZF Jacutinga, com maior realce morfoestrutural na porção centro-leste da área.

A fotointerpretação em fotografias aéreas na escala 1:25.000 permitiu o traçado de 807 lineamentos, principalmente negativos, com trend principal N40-50W e secundariamente para a direção N30-40E, como pode ser verificado nos diagramas de roseta da figura 3. Todavia foi possível verificar diferenças entre os traçados em diferentes escalas. A imagem de satélite apresentou baixa densidade de lineamentos na direção NE-SW, N-S e E-W, ao contrário do traçado realizado em fotografias aéreas com maior escala, onde foi possível caracterizar padrões recorrentes de estruturas lineares NESW e, com menor densidade, nas direções N-S e E-W. Estes resultados possibilitaram comparar e correlacionar os lineamentos fotointerpretados com feições descritas em campo. 


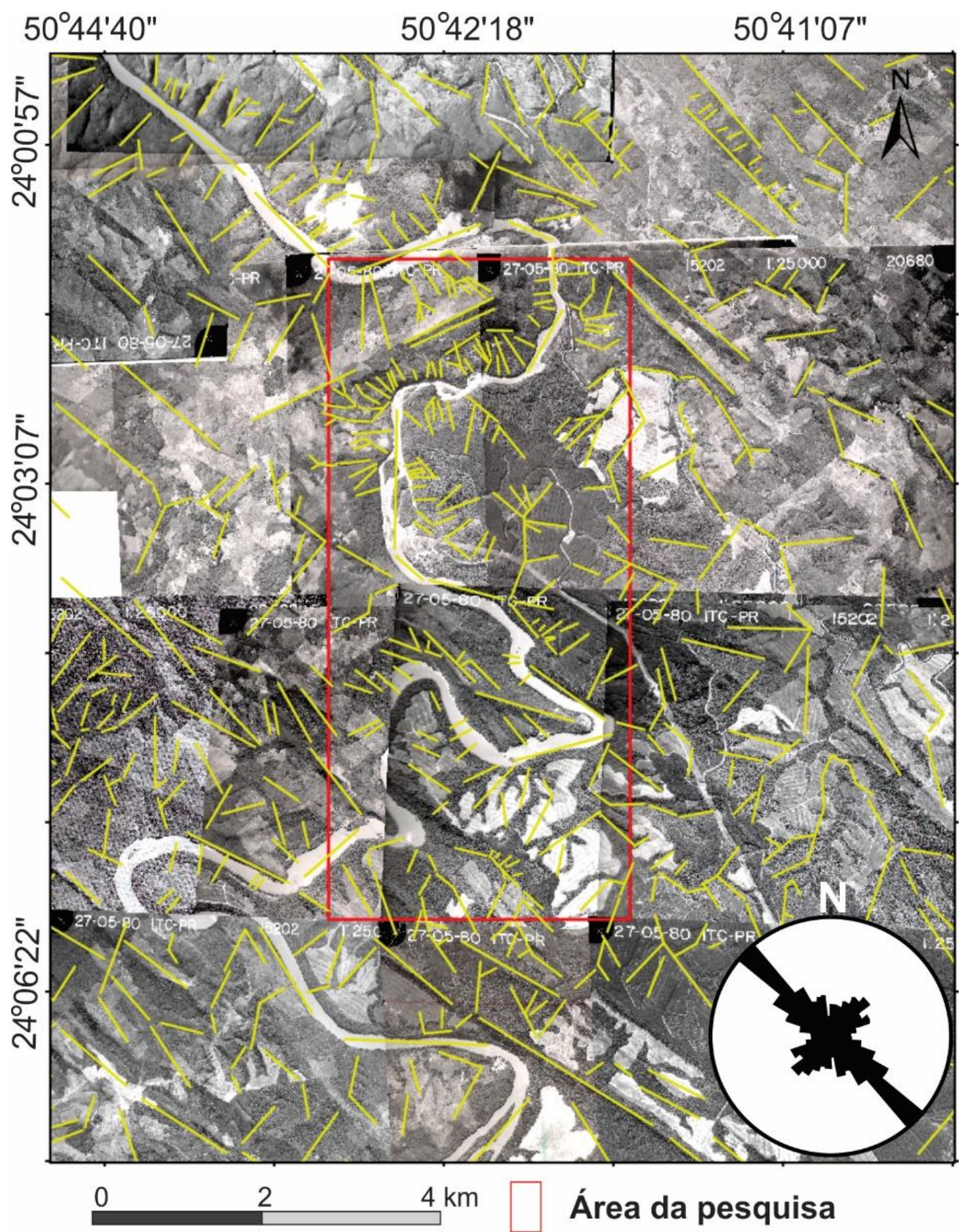

Figura 3 - Fotointerpretação de lineamentos de $1^{\circ}$ ordem e $2^{\circ}$ ordem. O diagrama de roseta de comprimento aponta trend estrutural das estruturas maiores com rumo principal N35-55W e, secundariamente, no rumo N20-30E. Há, ainda, traços menores nas direções N-S e E-W.

\section{Análise de Dados de Campo}

As descontinuidades mais expressivas mapeadas na região de estudo caracterizam tanto sistemas de juntas fechadas ou abertas com ou sem preenchimento mineral, quanto a falhas de transcorrentes, falhas normais oblíquas e raras inversas.

Nos afloramentos com estruturas rúpteis bem formadas as fraturas foram interpretadas de acordo com as características e relações geométricas do modelo de cisalhamento rúptil puro e, em estreitas zonas de falhas, de acordo com o modelo de cisalhamento simples do tipo Riedel, com geração de fraturas Y, R e R' e escalonadas (tipo gashs). Os dados de estrias e steps obtidos nas falhas formadas por cisalhamento simples permitiram a análise do paleotensão.

As famílias de fraturas (juntas e falhas) observadas em cada um dos afloramentos exibem predomínio de mergulhos empinados até subverticais e estão direcionadas tanto para NE- 
SW quanto NW-SE (Figura 4), havendo direções pouco frequentes entre N-S e NNW-SSE. Para uma comparação estatística foram confeccionados diagramas estruturais com a somatória de dados tanto da soleira de diabásio quanto das unidades sedimentares (Figura 5). Isto permitiu a determinação dos principais trends que afetam as unidades e sua correlação temporal.

Os diagramas exibem direções estruturais semelhantes para as diferentes unidades pesquisadas, principalmente para famílias de estruturas com direção NE-SW, com moda de N50-60E, seguido de estruturas com direções N60-70E, N40-50E e N30-45W. Os diagramas de contorno evidenciam o predomínio de fraturas verticais com mergulho para NW. Tais conjuntos de estruturas foram interpretados como geneticamente associadas aos planos de falhas transcorrentes.

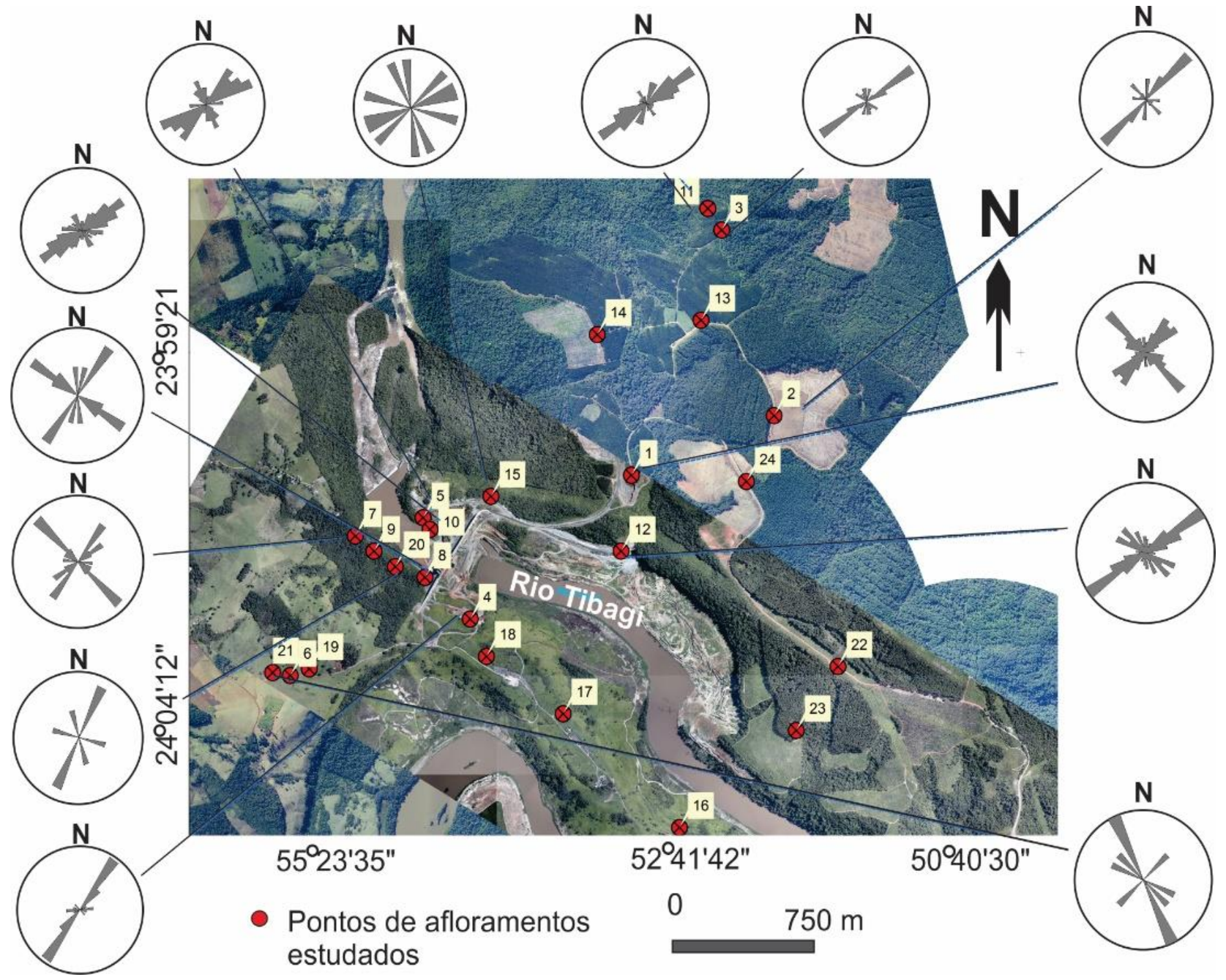

Figura 4 - Localização dos pontos onde foram levantadas as fraturas (juntas e falhas) e respectivos diagramas de rosetas com os principais trends locais dos sistemas de fraturas (juntas e falhas).

Em relação às unidades sedimentares, a Formação Palermo com afloramentos próximos ao túnel de desvio e câmara de carga (Ponto 15, Figura 4), apresenta principalmente fraturas de direções entre N40-60E e secundariamente N010W e N60-70W.

A Formação Irati (Ponto 4, Figura 4) apresenta um predomínio de fraturas com direção N40-60E e secundariamente N20-30W, enquanto a Formação Serra Alta (ponto 12, Figura 4) apresenta direção principal N40-60E e direção secundária N50-60W. Devido às características reológicas destas formações são pouco frequentes as observações de indicadores cinemáticos, ou seja, as falhas são caracterizadas pela existência de elementos típicos como a concorrência de fraturas conjugadas do tipo $\mathrm{R}$ e R' e formação de brechas e até gouges.

Já a distribuição de fraturas na soleira da Formação Serra Geral (ponto 1, Figura 4) apresenta duas concentrações, ocorrendo feições rúpteis com indicadores cinemáticos tanto para NE-SW quanto para NW-SE. Ali foi obtido o maior número de atitudes estruturais ( $\mathrm{n}=226)$, não só como consequência de sua maior área de exposição na área de estudo, mas também porque 
a reologia do diabásio é propícia à formação e preservação de estruturas mesoscópicas de falhas.

A integração entre os diagramas possibilitou deduzir que os pulsos tectônicos do sistema NESW e NW-SE são de idade máxima do Cretáceo Superior ou até paleogênicas (Paleocenas ou Eocenas), pois afetam todo o empilhamento estratigráfico da região. Estas estruturas geológicas podem estar relacionadas às reativações de sistemas de falhas que interceptam a região, tais como a $\mathrm{ZF}$ Jacutinga. Já as estruturas N-S e E-W são menos frequentes e neoformadas a partir das paleotensões que incidiram sobre as unidades geológicas locais. Cada família de fratura representativa encontrada é descrita a seguir, destacando suas características e singularidades.

(a) Família NE-SW - As descontinuidades associadas a esse sistema são recorrentes em todos os 21 afloramentos estudados, se manifestam por meio de fraturas planares e, por vezes, anastomosadas. Quando abertas, as fraturas são preenchidas por minerais carbonáticos de cálcio e óxido de manganês e em menor proporção quartzo e zeólitas.

Os planos de falhas ocorrem com menor frequência do que as juntas, porém configuram descontinuidades com maior expressão regional e são representadas por estruturas transcorrentes de cinemática dextral (Y), com pares conjugados sinistrais (R') e fraturas escalonadas (R). Em soleira de diabásio (ver Figura 4, Ponto 1) foram observadas diversas feições de direção NE-SW (Figura 6A) com destaque para zonas de cisalhamento e falhas com cinemática dextral, preenchidas por carbonatos, veios de quartzo e esparsos cristais de pirita.

Em rochas sedimentares de menor competência foram identificadas juntas escalonadas e pares conjugados de falhas planares com movimento dextral (Figura 6B). As fissuras preenchidas e zonas de falhas com óxido de manganês evidenciam um ambiente tectônico transtensivo. À jusante da barragem (Figura 4, Ponto 8) foram descritas juntas de cisalhamento no maciço rochoso e uma zona de cisalhamento dextral, com fissuras abertas e percolação de água (Figuras 6C e 6D).
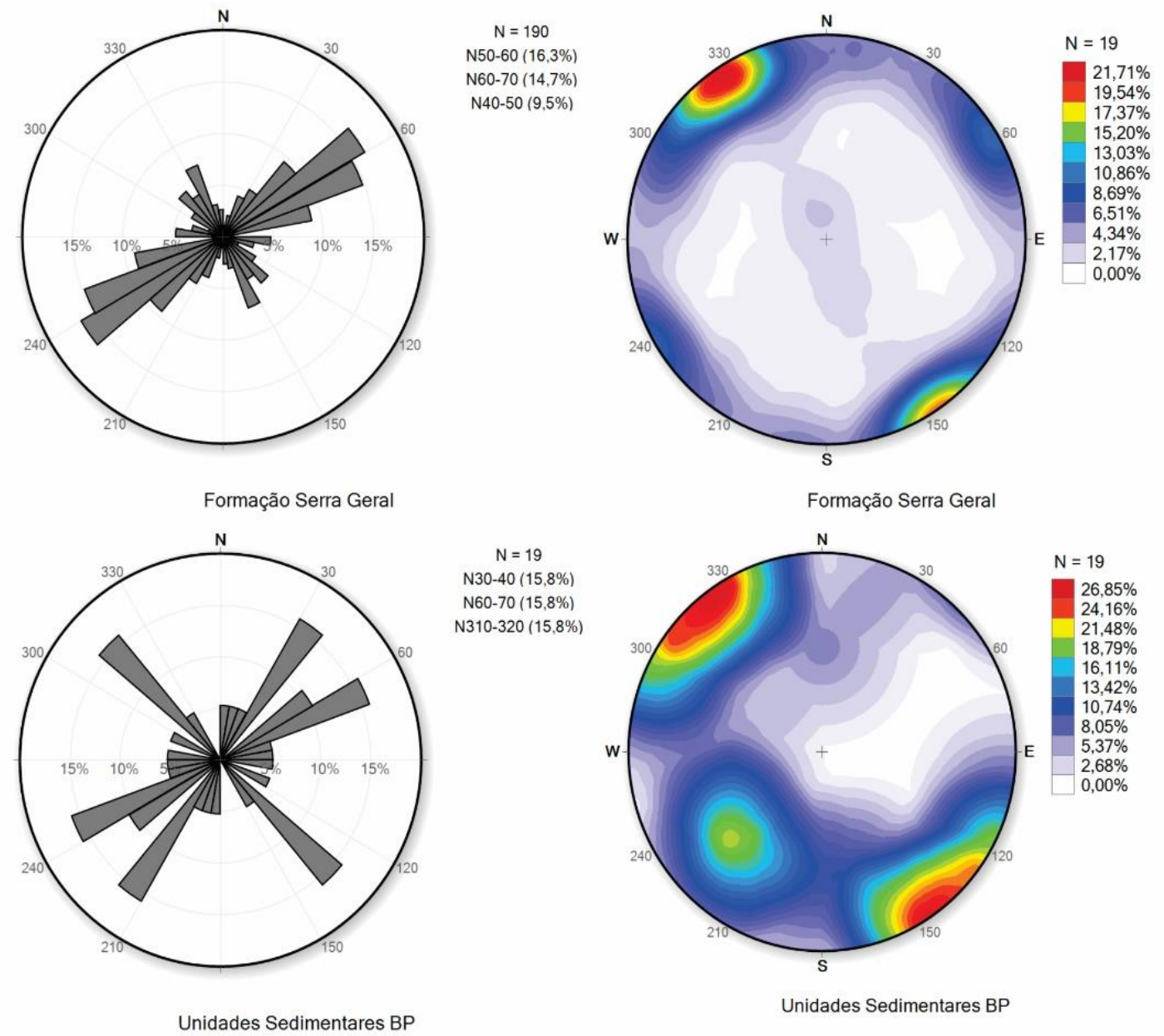

Figura 5 - Diagrama de roseta e de contorno das fraturas obtidas em levantamento de campo da soleira de diabásio (Formação Serra Geral) e do conjunto das unidades sedimentares da Bacia do Paraná (BP) cada unidade estratigráfica. 

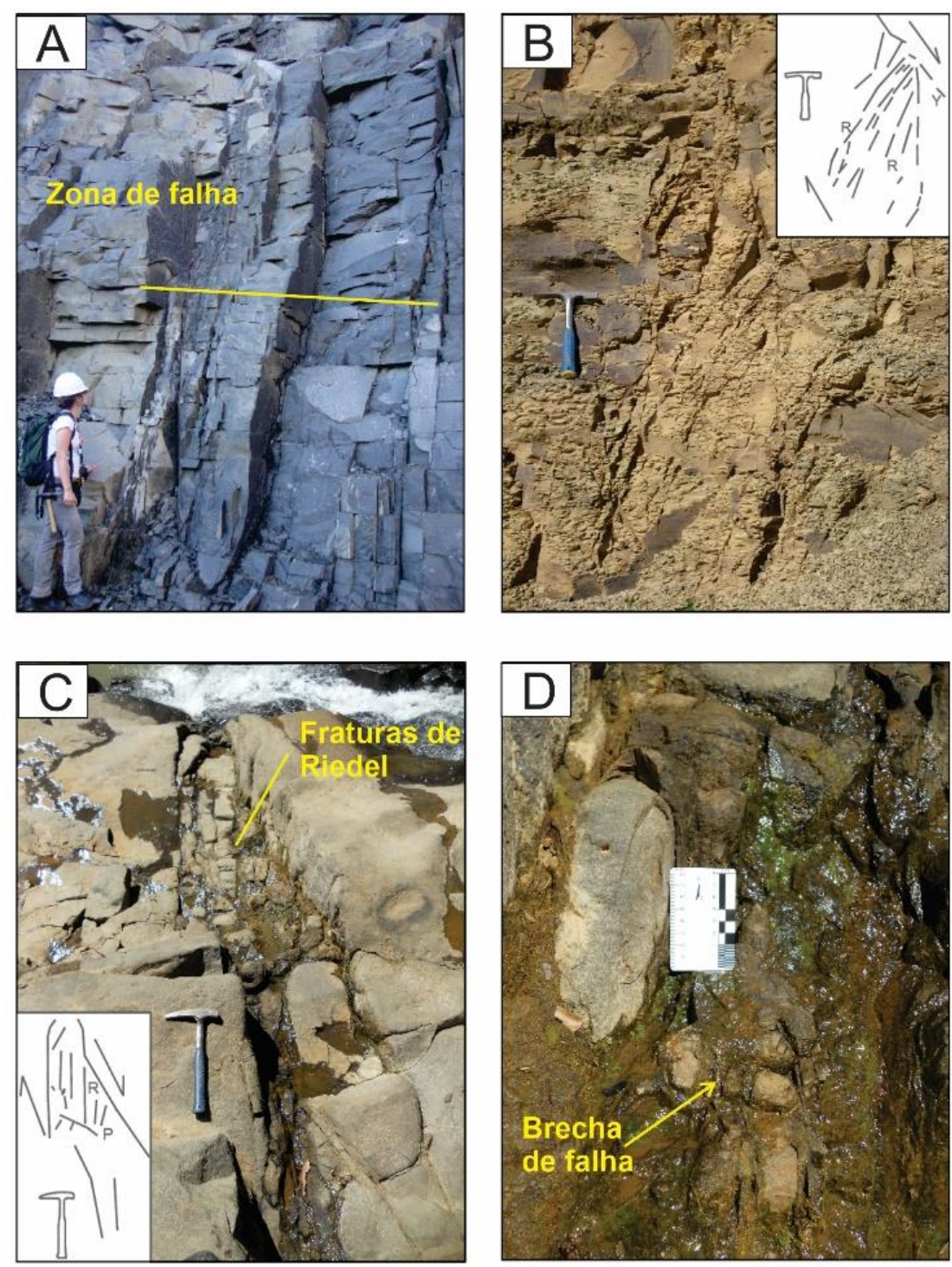

Figura 6 - Descontinuidades estruturais NE-SW: (A) e (B) mostram zonas de falha densas e subverticais em escala variável, com geração de brechas de falhas e rupturas planas a curviplanares; (C) e (D) apresentam brechas de falha: a primeira mostra fraturas conjugadas $\mathrm{R}$ caracterizando zona de falha dextral com formação de brechas em uma espessura de $0,5 \mathrm{~m}$; a segunda mostra a formação de brechas onde há percolação de água subterrânea.

Em rochas sedimentares de menor competência foram identificadas juntas escalonadas e pares conjugados de falhas planares com movimento dextral (Figura 6B). As fissuras preenchidas e zonas de falhas com óxido de manganês evidenciam um ambiente tectônico transtensivo. À jusante da barragem (Figura 4, Ponto 8) foram descritas juntas de cisalhamento no maciço rochoso e uma zona de cisalhamento dextral, com fissuras abertas e percolação de água (Figuras 6C e 6D).

(b) Família NW-SE - As fraturas NW-SE são planares a curviplanares e se manifestam de forma mais espaçadas com menor grau de penetratividade no maciço em relação ao sistema NE-SW. As juntas são classificadas como subpersistentes e persistentes no contexto de superfícies de cisalhamento rúptil. As paredes

das rupturas empinadas são planas, em geral polidas com slickensides ou slickenlines caracterizando falhas que possuem espaçamento métrico a decamétrico, fechadas e abertas podendo estar preenchidas por óxido de manganês e carbonato de cálcio.

As falhas que configuram essa família possuem cinemática predominantemente sinistrais, com fraturas conjugadas para NE-SW. Os melhores exemplos de indicadores cinemáticos transcorrentes de direção NW-SE foram localizados na soleira de diabásio (Figura 4, Pontos 1 e 10), onde se verificam veios de calcita rompidos em zona de falha, com exposição de estruturas de falha em flor positiva. Há frequentes zonas de cisalhamento, como mostra a figura 7, caracterizadas por intensa brechamento nas paredes. Há falhas transtensivas 
com estrutura em flor negativa (Figura 8A) e falhas normais também geradas por regime transtensivo. Todavia essas estruturas são pouco frequentes ou sistemáticas. Pequenas falhas com direção NW-SE e baixo ângulo de mergulho ocorrem nas intrusivas básicas da Formação Serra Geral, porém não são correlacionadas a eventos tectônicos regionais e constituem juntas de alívio com espaçamento milimétrico, interpretadas como geradas pela exumação da soleira.

Nas rochas sedimentares as feições de direção NW-SE em geral ocorrem predominantemente como juntas, porém no siltito da Formação Serra Alta foram identificadas famílias de fraturas com abertura microscópica que caracterizam juntas de cisalhamento ou estreitas zonas de falha com rejeito decimétrico a métrico.

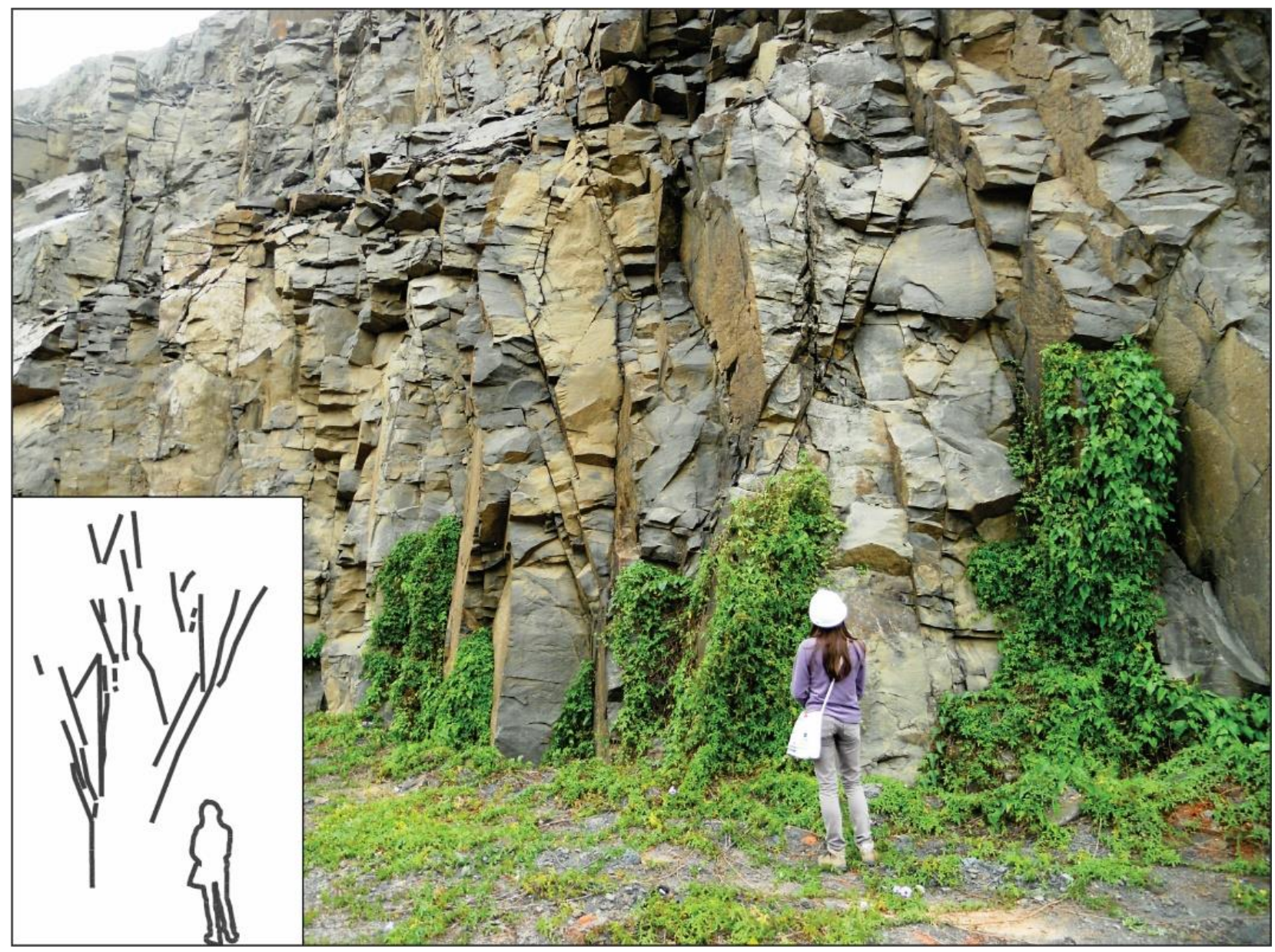

Figura 7 - Zona de falha NW-SE transcorrente com estruturas em flor do tipo tulipa.

(c) Família E-W - Esta família de fraturas é marcada por feições planares a anastomosadas, o que resulta em variação de atitude entre as direções de N80W e N80E. São sistêmicas, com penetratividade densa onde ocorrem como zonas de fraqueza do maciço. Normalmente apresentam-se planares, lisa a irregulares. Em sua maioria são juntas fechadas, porém há planos de falhas, configurando feições longas e retilíneas de regime transcorrente levemente oblíquo com cinemática sinistral (Figura 8B).

(d) Família N-S - Essa família de fraturas ocorre com menor frequência em relação às demais. As estruturas associadas apresentam-se bem espaçadas, com distâncias métricas entre cada plano de fraqueza e são caracterizadas como juntas planares, levemente curvilíneas não persistentes. As superfícies de ruptura em geral são planas lisas e polidas, localmente irregulares e rugosas.

Em afloramento da Formação Palermo (Figura 4, Ponto 3) e na pedreira de diabásio (Figura 4, Ponto 1), foram observadas descontinuidades com brechas de falhas $\mathrm{e}$ estruturas em flor negativa (Figuras 9A e 9B), configurando cinemática oblíqua de sentido antihorário.

Este sistema é formado por estruturas conjugadas do sistema de falha NE-SW. Nos sedimentos da Formação Serra Alta foi possível estabelecer uma relação espacial entre as demais famílias de fraturas, onde se observa o plano de fratura $\mathrm{N}-\mathrm{S}$ cortado pelas demais estruturas (Figura 9C).

862 São Paulo, UNESP, Geociências, v. 38, n. 4, p. 853 - 869, 2019 

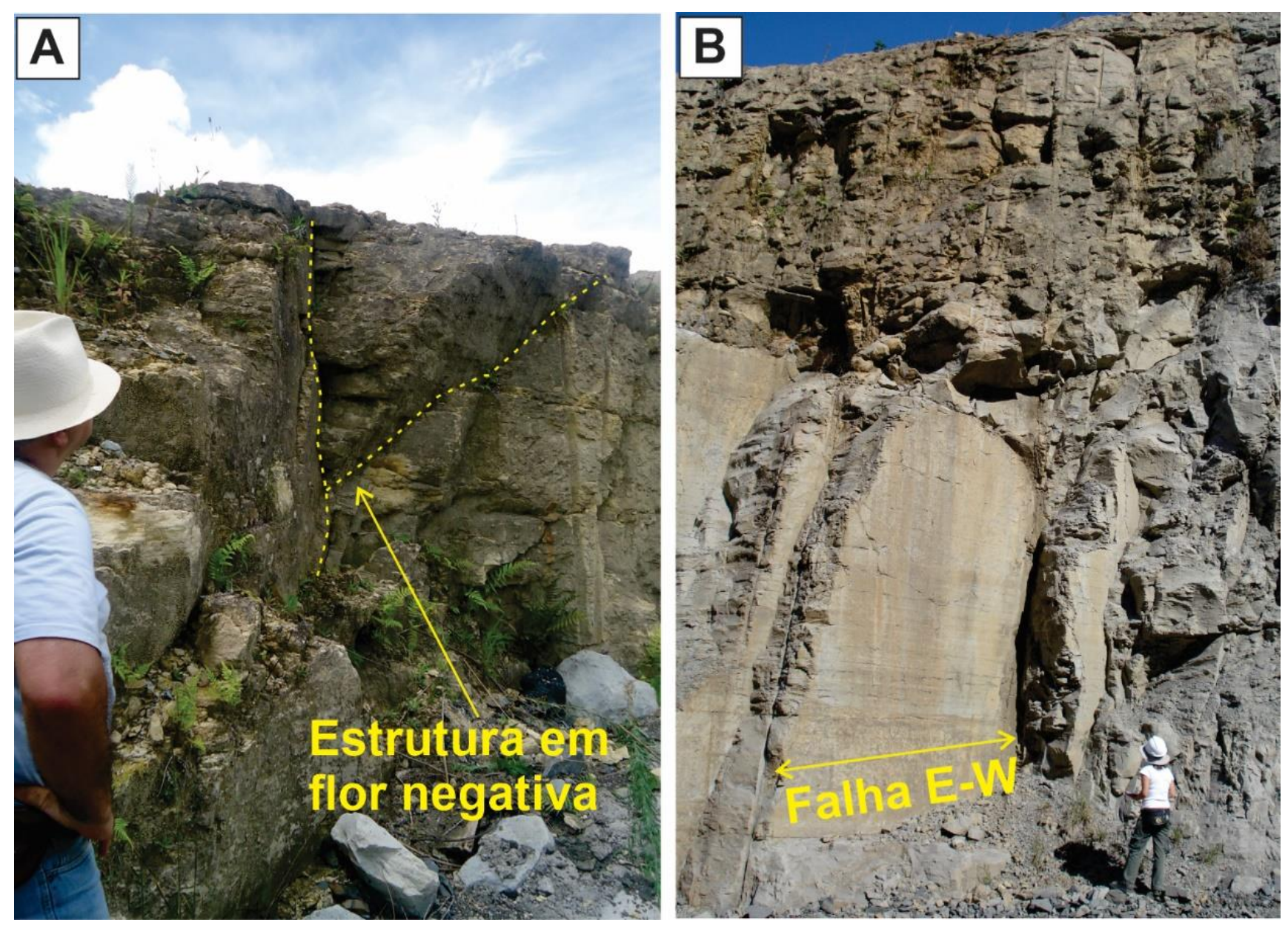

Figura 8 - (A) Falha transcorrente NW-SE com estrutura em flor negativa; (B) falha E-W em siltitos da Formação Palermo evidenciado indicadores cinemáticos sinistrais.

\section{Análise Cinemática e Dinâmica}

Baseando-se nas medidas da geometria e de indicadores cinemáticos (falhas conjugadas, Figura 10A; slickensides e steps, Figura 10B; critério R, Figura 11) foram obtidos os paleotensores responsáveis pela deformação rúptil do substrato rochoso no entorno da UHE Mauá. Com a finalidade de identificar estruturas predispostas e/ou suscetíveis a reativações ou acomodação do maciço sob o reservatório e a barragem, foi executada a análise e interpretação das paleotensões responsáveis pela antiga tectônica na região de estudo.

Os dados utilizados representam um total de 86 atitudes de elementos estruturais em falhas que segmentam todas as unidades geológicas mapeadas no entorno da UHE Mauá. A maioria dos dados $(\mathrm{n}=75)$ foi obtida na soleira de diabásio e os demais nas rochas sedimentares.

A análise dos dados tomados em conjunto, gerou diagramas de densidade de paleotensões (Figuras 12 e 13), confeccionados a partir de reunião de diagramas de paleotensão individualizados para os diversos afloramentos visitados (Figura 4). A maior frequência e acúmulo estatístico de esforços, característicos de regimes de deformação direcionais, são representados por isolinhas identificadas por cores estando claro que $\sigma_{1}$ e $\sigma_{3}$ estão horizontalizados ou com baixo ângulo e $\sigma_{2}$ vertical ou empinado. No caso da figura 12, o eixo de paleotensão máxima $\sigma_{1}$ está posicionado em um campo de tensão entre N20-40W / S20$40 \mathrm{E}$ com alguma dispersão para NNE-SSW. No caso da figura 13 a paleotensão máxima está posicionada em campo de tensão com variação ENE-ESE e WNW-WSW.

A partir da análise dos eixos de paleotensões e da correlação com dados de estudos anteriores, (Strugale et al., 2007), foi possível estabelecer dois pulsos de deformação rúptil distintos aqui denominados de D1 e D2, responsáveis pela geração e reativação das fraturas presentes na área de estudo. A individualização destes regimes de esforços foi deduzida por meio da diferença das características geométricas e cinemáticas entre as descontinuidades e, principalmente devido à relação espacial das concentrações de campos máximos de esforços $\sigma_{1}, \sigma_{2}$ e $\sigma_{3}$. 

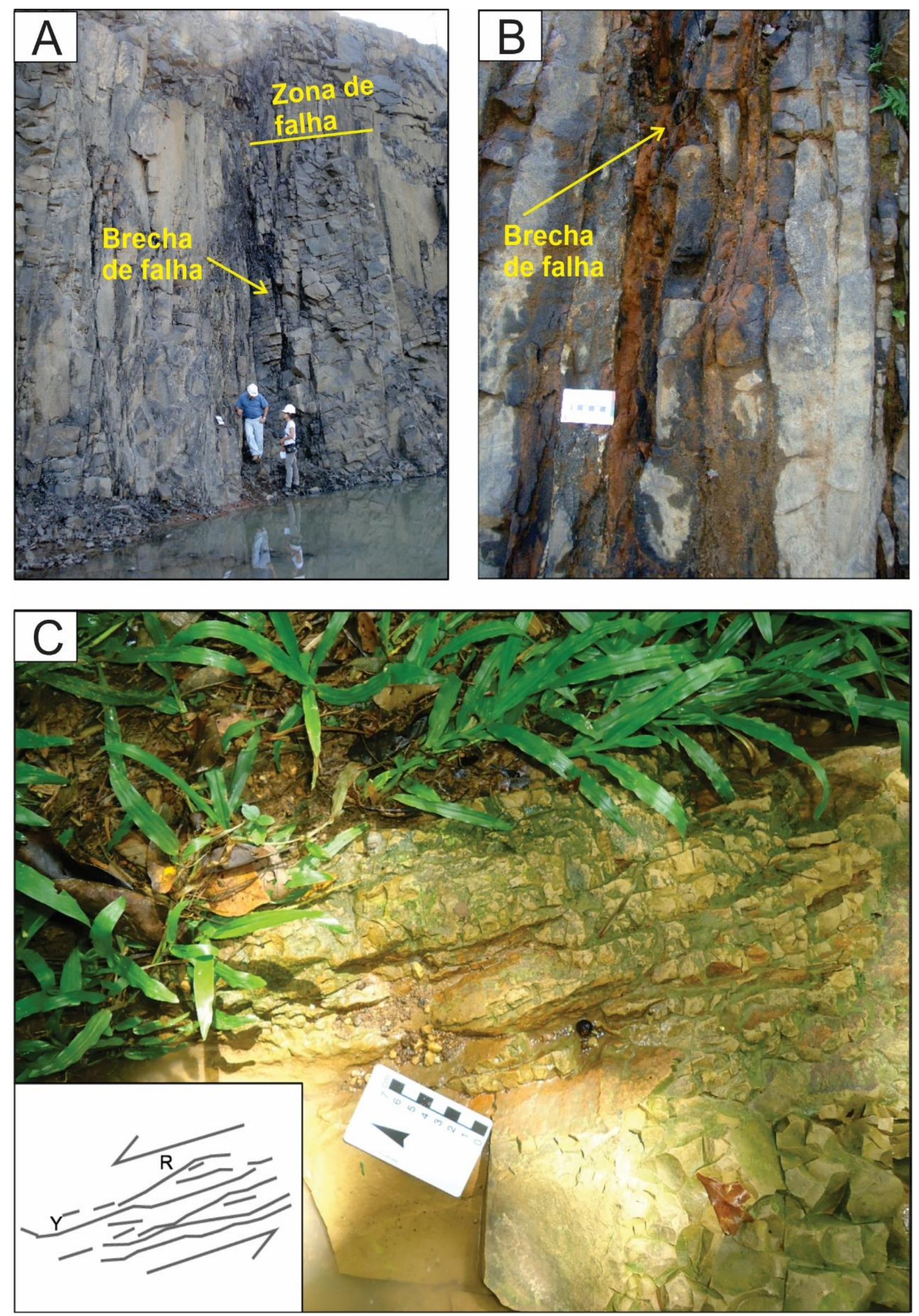

Figura 9 - Zona de falha de direção N-S. (A) planos contínuos fechados ou brechados, planares a curviplanares na soleira de diabásio e (B) planos com brecha e gouge também no diabásio; (C) formação de brecha de falha em siltitos da Formação Serra Alta. 

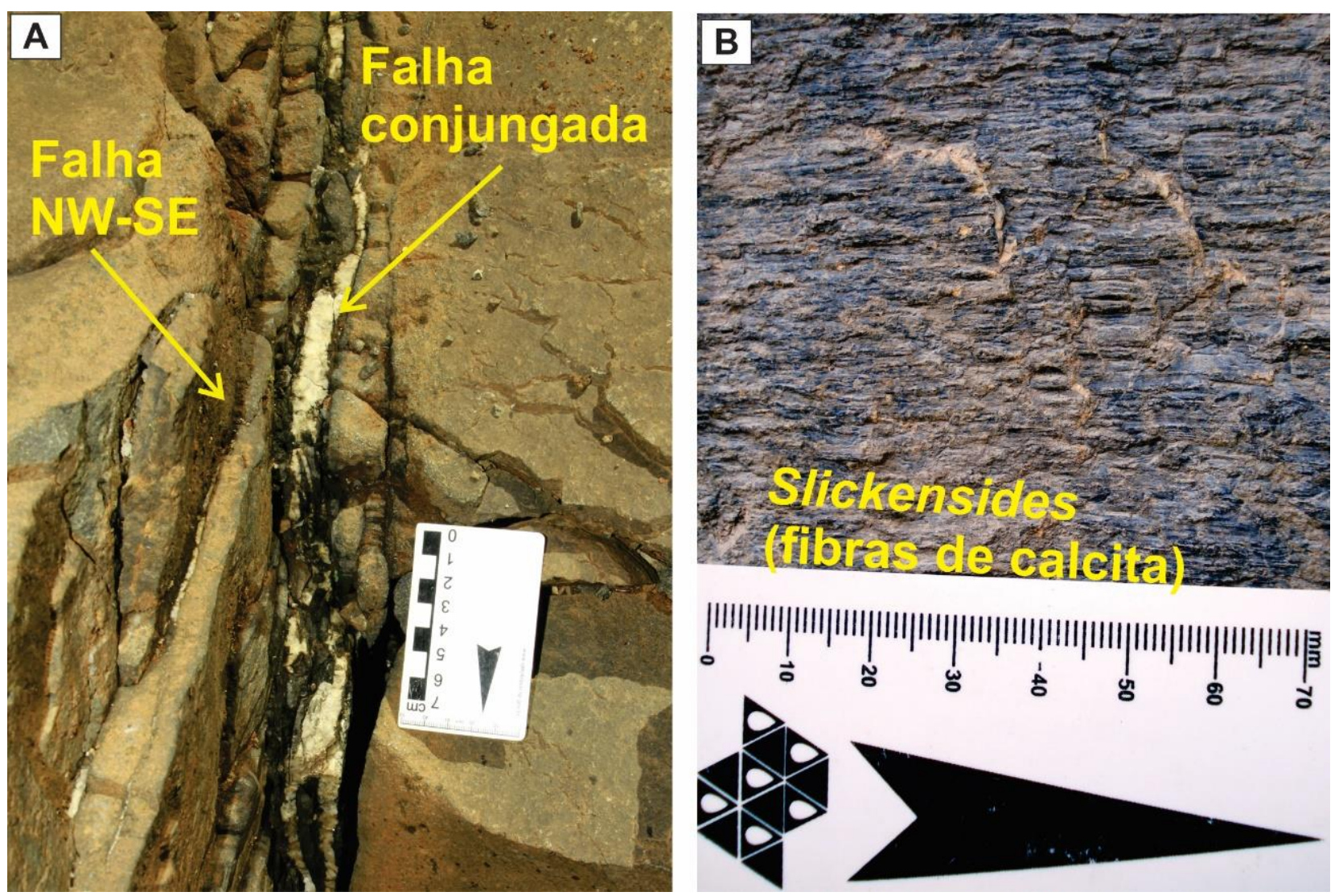

Figura 10 - Indicadores cinemáticos utilizados para a análise estrutural: (A) falhas conjugadas em diabásio com indicação de cinemática dextral; (B) crescimento fibroso com steps congruentes mostrando cinemática sinistral.
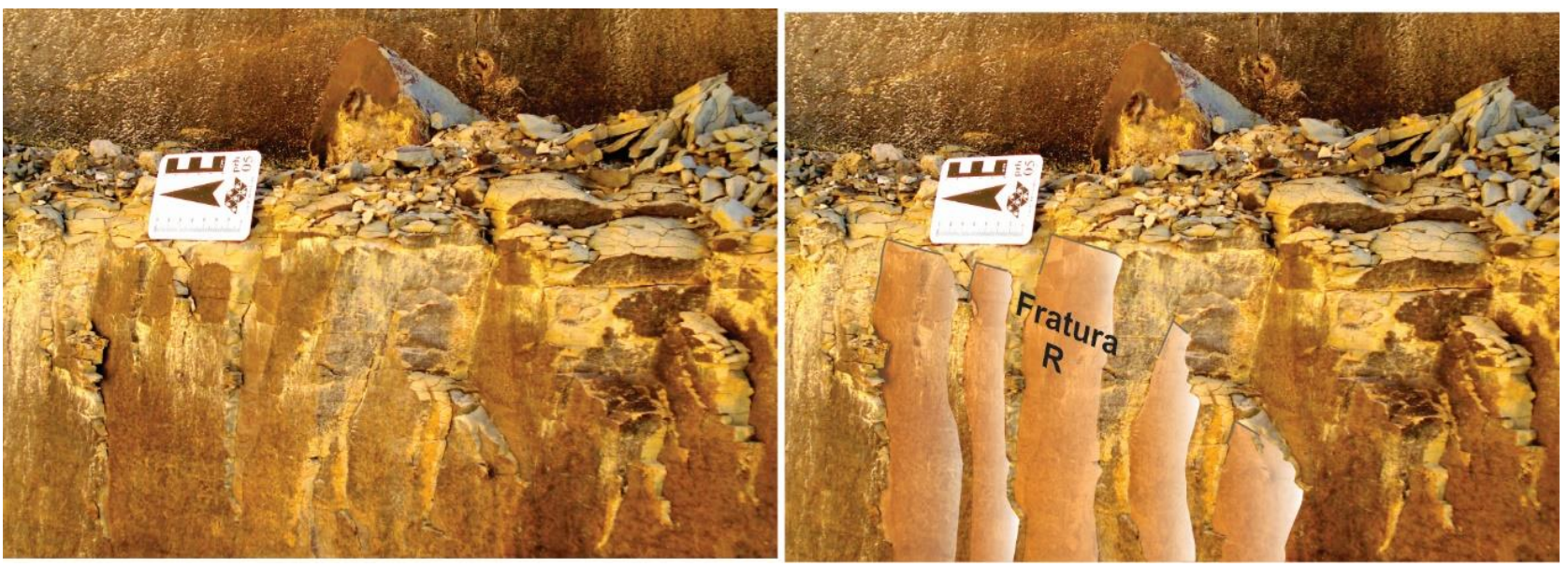

Figura 11 - Indicadores cinemáticos utilizados para a análise estrutural: arenitos finos da Formação Palermo com o critério R de Petit (1987) caracterizando cinemática dextral (a seta da plaqueta da escala marca o movimento do bloco ausente).

Pulso de deformação D1 - As estruturas rúpteis associadas a este pulso são produto de uma tectônica transtensional. As falhas são dextrais oblíquas de direção N40-50W, antitéticas às de direção N10-20W e conjugadas sinistrais às de direção N40-50E (Figura 12). Tais descontinuidades apresentam expressão local, restrita a pequenas extensões de alguns afloramentos levantados com um total de 29 medidas.

O produto dessa deformação é observado tanto na soleira de diabásio quanto nas rochas sedimentares da Formação Palermo. No diabásio há dados de paleotensão que variam em um campo entre NNW-SSE e NNE-SSW. Falhas em rochas ígneas são caracterizadas por estruturas do tipo flor negativa, havendo bandas de cisalhamento de direção NW-SE, em geral com cinemática dextral.

Já nas unidades sedimentares, foi obtido um quadro com maior acúmulo estatístico de paleotensões na direção N20-30E. Nesse caso predominam apenas indícios de cinemática sinistral, pois as amostras representam somente 
$15 \%$ do total de dados levantados.

O registro da deformação resultante do pulso D1 nos arenitos da Formação Palermo, é marcado por planos de falhas (Y) N50E e fraturas escalonadas sintéticas do tipo R de Riedel, com direção NE-SW, ambos de cinemática sinistral. Na região da câmara de carga (Figura 4, Ponto 3), a estrutura observada com geometria de flor negativa de direção N10W e cinemática sinistral foi interpretada como uma fratura R' do sistema conjugado de Riedel.

Pulso D2 - Esse pulso tectônico expõe a maior quantidade de falhas com indicadores cinemáticos, tanto impressos nas rochas básicas quanto sedimentares. A geometria das estruturas rúpteis retrata um quadro complexo de cisalhamento direcional com grande quantidade de zonas de cisalhamento, famílias de falhas com frequentes brechas e outras características, além de outras características rúpteis. Neste pulso observa-se uma dispersão do $\sigma_{1}$, principalmente na soleira de diabásio. O esforço máximo está presente em um campo cuja dispersão varia cerca de $20^{\circ}$ entre ENE-WSW e WNW-ESE. Nesse estágio foram formadas fraturas conjugadas de acordo com o modelo de Riedel, caracterizadas por trend estrutural entre N40-60E e cinemática dextral, bem como tendo gerado pares conjugados sinistrais na direção N40W (Figura 13). Os dados utilizados nesta análise representam um total de 57 atitudes de planos de falhas.
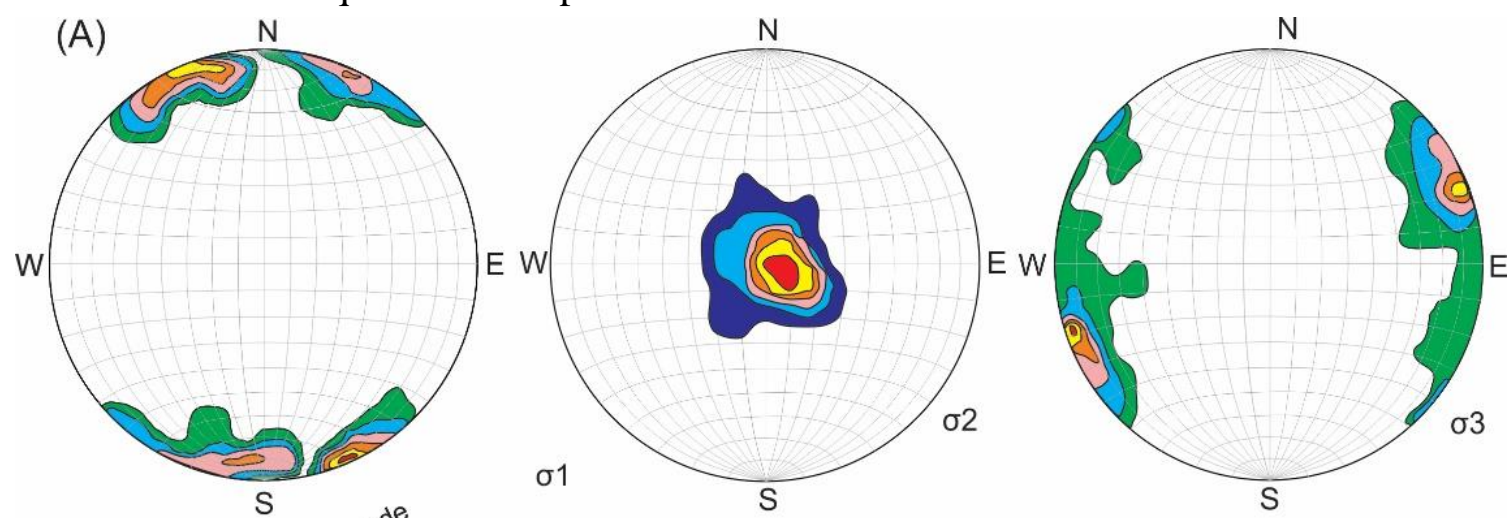

(B)

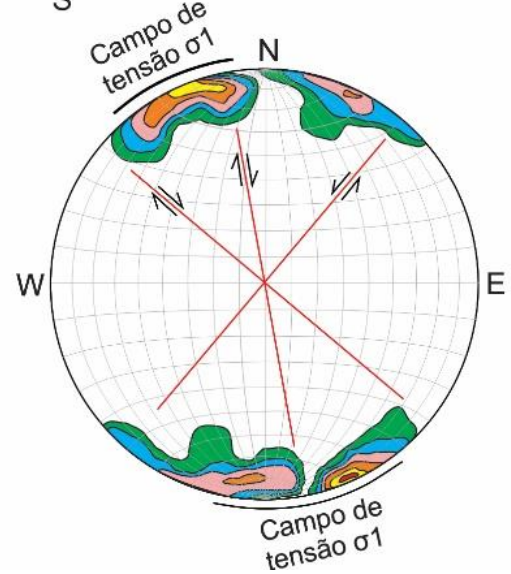

$\%$ Incidência

de Eixos de tensão
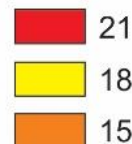

$\square 12$
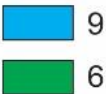

Figura 12 - Diagramas de contorno com os campos de paleotensão que formaram falhas relacionadas ao pulso D1; (A) diagramas de contorno para os eixos $\sigma_{1}, \sigma_{2}$ e $\sigma_{3}$ e (B) salientando o campo de paleotensão $\sigma 1$ e as falhas transcorrentes nucleadas de acordo com a variação do eixo máximo no pulso D1.

O campo de tensão máxima neste pulso é responsável pela formação de falhas E-W dextrais, podendo eventualmente haver falhas sinistrais subsidiárias. Estas fraturas, por vezes, seccionam as demais feições rúpteis identificadas em campo. As superfícies das falhas E-W configuram descontinuidades longas e planares com concentração de cisalhamento, porém com baixa expressão regional. Nas unidades sedimentares este pulso é representado por feições de falhas pouco expressivas, exceto nos siltitos da Formação Serra Alta. No Ponto 4
(Figura 4), ocorre a conjunção de fraturas de direção E-W com truncamento entre planos, o que remete ao modelo de fraturamento, caracterizando a fratura N85E/85SE como do tipo $\mathrm{Y}$, e as fraturas conjugadas N80W/85SE e N64E/84NW, respectivamente como $R$ e $X$, todos com cinemática dextral. Já nas soleiras de diabásio os pulsos transtensionais formam geometria em flor negativa e superfícies de cisalhamento provocada pela paleotensão $\sigma 1$ na direção E-W, mesmo com sutil dispersão para WNW-ESE, ocorrendo fraturas abertas de 
direção N40-50W, relacionadas ao regime transtensivo do pulso de deformação D2, geralmente preenchidas por calcita bem cristalizada, com intercrescimento de pirita euédrica em planos de falhas, além de óxido de manganês em zonas de cisalhamento

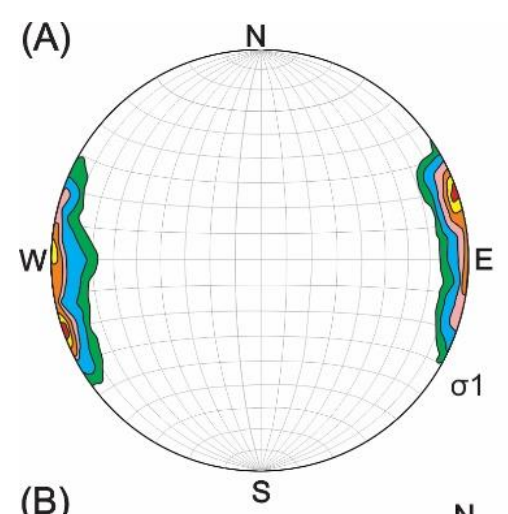

(B)

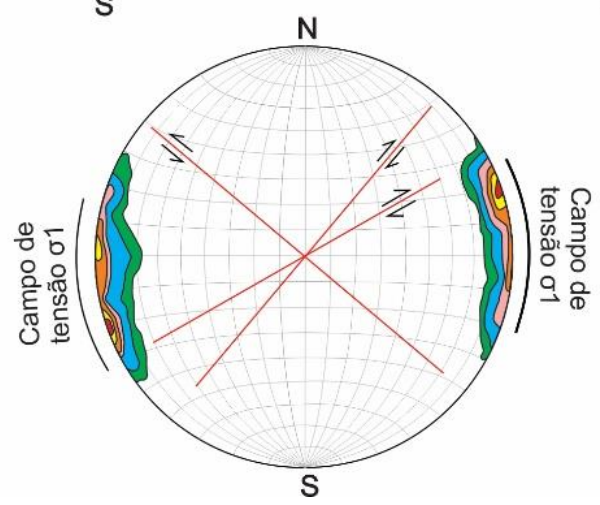

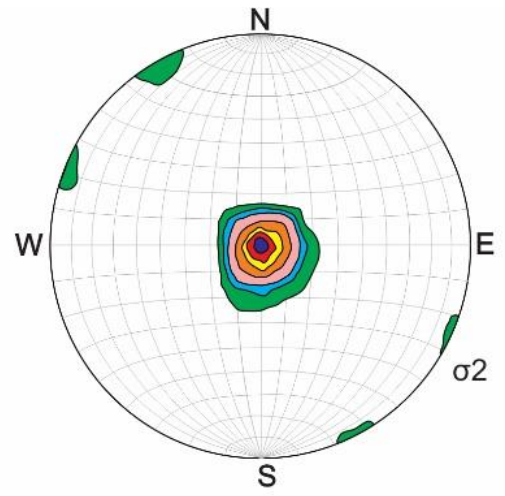

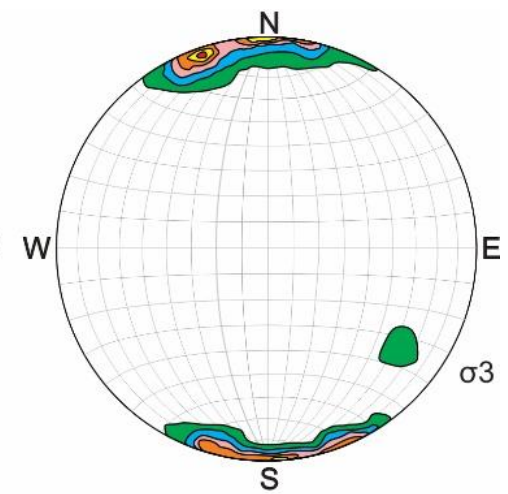

$\%$ Incidência de Eixos de tensão
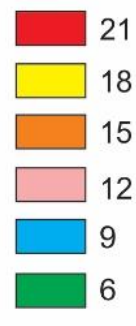

Figura 13 - Diagramas estruturais de paleotensões para as falhas relacionadas ao evento D2; (A) diagramas de contorno para os eixos $\sigma_{1}, \sigma_{2}$ e $\sigma_{3}$, (B) diagrama sinóptico representando a posição do eixo de paleotensão $\sigma_{1}$ e as falhas transcorrentes nucleadas de acordo com a variação da paleotensão no pulso D2.

\section{DISCUSSÃO}

A comparação e integração dos dados estruturais obtidos neste trabalho permitiram caracterizar dois pulsos de paleotensão locais e consequentes deformações em rochas ígneas e sedimentares na região da UHE Mauá. Foram identificados três possíveis zonas de maior fragilidade em virtude do controle estrutural imposto por grandes alinhamentos no Arco de Ponta Grossa. Tais alinhamentos induzem a coalescência de diques e extensas zonas de falhas de direção NW-SE, seccionadas por zonas de falhas de direção NE-SW, principalmente na área de influência da ZF Jacutinga.

As unidades e estruturas geológicas relacionadas ao soerguimento do arco são pervasivas em toda a área de estudo e conferem ao relevo feições morfoestruturais peculiares à região, principalmente sob a forma de diques e soleiras. Em área próxima Strugale et al. (2007) definiram as denominadas ZF Tamarana, ZF Mauá da Serra, ZF Rio Pereira, caracterizadas por uma maior presença de diques de diabásio, definidos em imagens como fotolineamentos que configuram altos estruturais e topográficos.
O levantamento possibilitou a correlação de elementos estruturais com a ZF Tamarana que compõe o conjunto de alinhamentos retilíneos e anastomosados de direção NW-SE, definidos a norte e noroeste da área de estudo e a ZF Mauá da Serra ao sul e sudoeste. Tais alinhamentos são pouco visíveis em imagem de satélite e fotografias aéreas na região estudada, em função de maior ocorrência de soleiras de diabásio no local.

Os lineamentos de direção NE identificados tanto em imagens de satélite, quanto em fotografias aéreas, apresentam traços mais segmentados pouco contínuos e espaçados, correlacionados à ZF Jacutinga que, segundo Rostirolla et al. (2000), ocorrem como feições alternadas de altos e baixos alinhados a N50$60 \mathrm{E}$ na forma de falhas em feixes ou en échelon.

As características geológicas observadas em campo indicam deformações de regime rúptil, identificadas por falhas transcorrentes antigas em níveis crustais superiores e juntas associadas. Em afloramentos, tais desconti- 
nuidades foram separadas conforme trends preferenciais em NE-SW, NW-SE, N-S e E-W. As famílias de falhas e juntas mais pervasivas na área de estudo pertencem à família NE-SW seguidas de falhas e juntas de direção NW-SE que, conforme mencionado anteriormente, foram correlacionadas, respectivamente à $\mathrm{ZF}$ Jacutinga (NE-SW) e ao Arco de Ponta Grossa (NW-SE).

Em área adjacente Strugale et al. $(2003 ; 2007)$ identificaram dois eventos, aqui referidos como pulsos de deformação similares aos encontrados em região próxima à UHE de Mauá.

O trabalho aqui apresentado corrobora a interpretação daqueles autores, definindo para o evento inicial (D1) uma deformação progressiva e paleotensão $\sigma_{1}$ que pode ter rotacionada de NNW-SSE a NNE-SSW. O evento final (D2), gerado pela paleotensão máxima $\sigma_{1} \mathrm{E}-\mathrm{W}$, ou próxima a esse campo, é mais persistente e sistemático nas unidades meso-paleozoicas aflorantes na área de estudo. As descontinuidades relacionadas a essa deformação ocorrem na forma de conjuntos de falhas transcorrentes ou transtensionais, em geral de direção entre N40$60 \mathrm{E}$ e cinemática dextral, além de zonas de cisalhamento e fraturas abertas preenchidas por carbonato de direção N60-70E e grande quantidade de juntas associadas. Rostirolla et al. (2000) associam as reativações da ZF Jacutinga (NE-SW) de caráter dextral imediatamente após o magmatismo Serra Geral. Aqui foi identificado que esse pulso também formou um corredor de juntas e falhas de direção N40-50W com cinemática sinistral e, por fim, um corredor de juntas e falhas E-W. Essas deformações são compatíveis, em termos cinemáticos, com as estruturas descritas na Serra do Cadeado (Strugale et al. 2007).

O pulso D2 é compatível com a proposição de Melo et al. (1985) e Riccomini et al. (2004), que sugerem um campo de tensão estabelecido entre o Cretáceo Superior e o Neógeno com o mesmo trend daquele identificado na área de estudo.

\section{CONCLUSÕES}

$\mathrm{O}$ arcabouço geológico-estrutural, definido por meio do levantamento de campo e análise de lineamentos no relevo, evidenciam que o maciço rochoso é compartimentado pelas famílias de fraturas, NE-SW, NW-SE, E-W e N-S, da maior à menor pervasividade, respectivamente.

Os lineamentos de direção NW-SE representam morfoestruturas com maior realce em imagens de satélite e fotografias aéreas em função destes representarem feições tectônicas associadas ao Arco de Ponta Grossa. Os lineamentos na forma de falhas preenchidas por diques de diabásio sobressaem em relação às rochas sedimentares sob a forma de cristas alongadas. A análise dos dados gerou diagramas de paleotensão característicos de regimes transcorrentes ou transtensionais possibilitando interpretar pelo menos dois pulsos de deformação denominados, respectivamente, de D1 que representa um campo de tensão entre NNE-SSW e NNW-SSE e D2 que representa um campo de tensão entre ENE-WSW e WNW-ESE. A individualização destes esforços foi deduzida por meio da diferença das características geométricas e cinemáticas entre as falhas e também devido à relação espacial das concentrações de campos máximos de esforços.

O pulso D1 é pós-cretácico e apresenta poucos registros com indicadores cinemáticos nos litotipos mapeados, com falhas transtensivas e predomínio de direções estruturais NW-SE com planos retilíneos longos a anastomosados e bem espaçados que cortam as unidades rochosas da Formação Palermo e da Formação Serra Geral. As falhas são correlatas a eventos deformacionais ocorridos entre o Cretáceo e o Paleógeno, também observados por outros autores.

$\mathrm{O}$ pulso $\mathrm{D} 2$, possivelmente correlato ao neotectonismo entre o Neógeno e o Pleistoceno, afeta com maior intensidade progressivamente os maciços rochosos da região, caracterizado, principalmente, por falhas transcorrentes com componentes extensionais e juntas de direção NE-SW com planos retilíneos a anastomosados pouco espaçados, além de fraturas abertas e preenchidas e ocasionalmente zonas de cisalhamento com brechas e material gouge.

\section{AGRADECIMENTOS}

Os autores externam agradecimentos à Universidade Federal do Paraná, à COPEL-Cia. Paranaense de Energia e ao Instituto de Tecnologia para o Desenvolvimento - Institutos Lactec pelo apoio recebido ao longo o trabalho. 


\section{REFERÊNCIAS}

ANGELIER, J. Fault slip analysis and paleostress reconstruction. In: HANCOCK, P. L., (ed.). Continental Deformation. Oxford: Pergamon Press, p. 53-100. 1994.

CAMPANHA, G.A.C. \& SADOWSKI, G.R. Tectonics of the Southern Portion of the Ribeira Belt (Apiaí Domain). Precambrian Research, Amsterdam, v. 98, n. 1, p. 31-51, 1999

CORDANI, U.G.; BRITO NEVEZ B.B.; FUCK R.A.; PORTO R.; THOMAZ FILHO, A.; CUNHA F.M.B. Estudo preliminar de integração do Pré-Cambriano com os eventos tectônicos das bacias sedimentares brasileiras. Boletim Ciência Técnica Petróleo, Seção Exploração de Petróleo. 1984.

DOBLAS, M. Slickenside Kinematic Indicator. Tectonophysics. v. 295, p. 187-197, 1998.

FERREIRA, F.J.F. Integração de dados aeromagnéticos e geológicos: configuração e evolução tectônica do Arco de Ponta Grossa. São Paulo, 1982. 170p. Dissertação (Mestrado em Geofísica), Instituto de Geociências - Universidade de São Paulo.

FIGUEIRA, I.F.R. Caracterização Estrutural - Estratigráfica para seleção de alvos de reservatórios análogos no sistema petrolífero Ponta Grossa-Itararé na Bacia do Paraná Curitiba, 2004. Dissertação (Mestrado em Geologia). Departamento de Geologia, Universidade Federal do Paraná, 2004.

FREITAS, R.C. de Análise estrutural multimatemática do Sistema Petrolífero Irati-Rio Bonito, Bacia do Paraná. Curitiba, 113p. 2005. Dissertação (Mestrado em Geologia), Departamento de Geologia - Universidade Federal do Paraná,

MELO, M.S.; RICCOMINI, C.; HASUI, Y.; ALMEIDA, F.F.M.; COIMBRA, A.M. Geologia e evolução do sistema de bacias tafrogênicas continentais do sudeste do Brasil. Revista Brasileira de Geociências, São Paulo, v. 15, p. 193-201, 1985.

MILANI, E.J.; MELO, J.H. G.; SOUZA, P.A.; FERNANDES, L.A.; FRANÇA, A.B. Bacia do Paraná. Boletim Geociências Petrobras. Rio de Janeiro, v. 15, n. 2, p. 265-287, 2007.

MINEROPAR. Mapa geológico do Estado do Paraná. Folha Curitiba, Curitiba- PR. Escala 1:250.000. Mineropar S.AGoverno do Paraná. 2006.

PETIT, J.P. Criteria for sense of movement on fault surfaces in brittle rocks. Journal Structural Geology, v. 9, n. 516, p. 597608, 1987.

RICCOMINI, C.; SANT'ANNA, L.G.; FERRARI, A.L. Evolução geológica do Rift Continental do Sudeste do Brasil. In: MANTESSO-NETO, V.; BARTORELLI, A.; DAL RÉ CARNEIRO, C.; BRITO NEVES, B.B. (Coords). Geologia do Continente Sul-Americano - Evolução da Obra de Fernando Flávio Marques de Almeida. São Paulo, Petrobras, 2004.
ROSTIROLLA, S.P.; ASSINE, M.L.; FERNANDES, L.A.; ARTUR, P.C. Reativação de Paleolineamentos durante a Evolução da Bacia do Paraná - O Exemplo do Alto Estrutural de Quatiguá. Revista Brasileira de Geociências, v. 30, n. 4, p. 639-648, 2000.

SOARES, P.C. Tectônica sinsedimentar cíclica na Bacia do Paraná: controles tectônicos. Curitiba, 1991, 148p. Tese (Professor Titular) - Departamento de Geologia, Universidade Federal do Paraná.

SOARES, P.C.; ROSTIROLLA, S.P.; FERREIRA, F.L.F.; STEVANATO, R. $\mathrm{O}$ alto estrutural Pitanga-QuatiguáJacutinga na Bacia do Paraná: Uma estrutura Litosférica. In: CONGRESSO BRASILEIRO DE GEOLOGIA, 38, 1996. Boletim de Resumos...Salvador: Sociedade Brasileira de Geologia, 1996

STRUGALE, M.; ROSTIROLLA, S.P.; KULEVICZ, M.B.; MANCINI, F. Evolução estrutural do Arco de Ponta Grossa no Cretáceo a partir da análise de estruturas rúpteis no Grupo São Bento (Bacia do Paraná). In: SIMPÓSIO NACIONAL DE ESTUDOS TECTÔNICOS, 9, Armação de Búzios. 2003. Boletim de Resumos... Rio de Janeiro: Sociedade Brasileira de Geologia, 2003, p. 320-323.

STRUGALE, M.; ROSTIROLLA, S.P.; MANCINI, F.; PORTELA FILHO, C.V. FERREIRA, F.J.F.; FREITAS, R.C. Structural framework and Mesozoic-Cenozoic evolution of Ponta Grossa Arch, Paraná Basin, Southern Brazil. Journal of South American Earth Sciences, v. 24, p. 203-227, 2007.

VLB ENGENHARIA. Mapa geológico geral da UHE Mauá 0706-MA-DE-310-12-002-R0. Curitiba, 2007

ZALÁN, P.V.; WOLFF, S.; CONCEIÇÃO, J.C.; MARQUES, A.; ASTOLFI, M.A.M; VIEIRA, I.S.; APPI, V.T. Bacia do Paraná. In: G.P. RAJA GABAGLIA \& E.J. MILANI, Origem e evolução de Bacias Sedimentares. Rio de Janeiro: Petrobrás, 2a. ed., p. 135-164, 1990 